\title{
Early Insulin Release Following Suckling in Neonatal Lambs and Rabbits
}

\author{
R. J. Porter and J. M. Bassett \\ Nuffield Institute for Medical Research, University of Oxford, Oxford, England
}

\begin{abstract}
Summary. Developmental changes in the plasma insulin response to milk ingestion have been determined in neonatal lambs fed by bottle and in naturally suckled infant rabbits. In lambs at 4 days of age and older plasma insulin increased within $5 \mathrm{~min}$ of suckling and declined again before increasing to a second peak 60 to $120 \mathrm{~min}$ after the feed. The early insulin peak was not associated with any change in plasma glucose and was absent in lambs at 1 day of age. When the early insulin peak was absent the increase in plasma glucose following the meal was greater. The early, apparently reflex, release of insulin also occurred in some 'sham-fed' lambs. Atropine administration before feeding abolished the early peak in insulin. A marked early peak of insulin release, not accompanied by any consistent change in plasma glucose, was also observed in naturally-suckled infant rabbits at 1, 5, 10 and 15 days after birth.
\end{abstract}

Key words: Insulin, glucose, newborn, early insulin response to feeding, insulin in suckled infant, newborn lambs, newborn rabbits, atropine and insulin secretion.

The changes in plasma insulin concentration following a meal reflect the integrated functioning of neural and gastro-intestinal humoral anticipatory mechanisms as well as the stimulatory effects of increased metabolite concentrations in plasma. In man and other species the insulin responses to oral glucose and amino acid loads are significantly greater than those to similar loads given intravenously, showing that the gut amplifies these responses [1-3]. Furthermore in several species including man [4], dog [5], sheep [6], rat $[7,8]$, it has been shown that insulin concentrations rise within a few minutes of eating and before any increase in systemic plasma glucose concentration which might account for this change. Both insulinogenic gastro-intestinal hormones and the autonomic nervous system have been proposed as mediators of this extra insulin response. The question arises whether such a sophisticated integrated response is present in the newborn which is perforce unaccustomed to many of the stimuli provided by the presence of food within the gut, or whether it develops in the early postnatal period. To this end the insulin secretory responses to suckling in the neonates of two species, the sheep and rabbit, have therefore been studied.

\section{Material and Methods}

\section{Animals}

a) Lambs

Ten crossbred lambs, varying in age from 1 to 71 days and in weight from 2.75 to $30 \mathrm{~kg}$ were used. Animals required for experiments at an early age were removed from their mothers after a sufficient period of time (about $12 \mathrm{~h}$ ) for them to have had access to colostrum. Other lambs were removed from their mothers several days before their first experiment. The lambs were maintained on a diet of Denkavit (Rank, Hovis, McDougall) or Coopalac (Cooper Nutrition Products Ltd) milk preparations suitable for feeding to lambs. Feeding was by bottle or by suckling from a 'lamb bar'. Until 7 days of age lambs were given 4 feeds of $250 \mathrm{ml}$ daily, then 3 feeds daily each of $450 \mathrm{ml}$ up to one month and subsequently 3 feeds of $550 \mathrm{ml}$ daily. The animals also had ad-libitum access to hay and sheep pellets (Dixons).

\section{b) Rabbits}

Thirty-six litters of chinchilla rabbits were used. The litters and their does were kept in special two-compartment breeding cages with the facility for closing the partition between the two compartments. For studies at 1 day of age the doe was separated from her litter for $24 \mathrm{~h}$ as soon after littering as possible $(<12 \mathrm{~h})$, but 


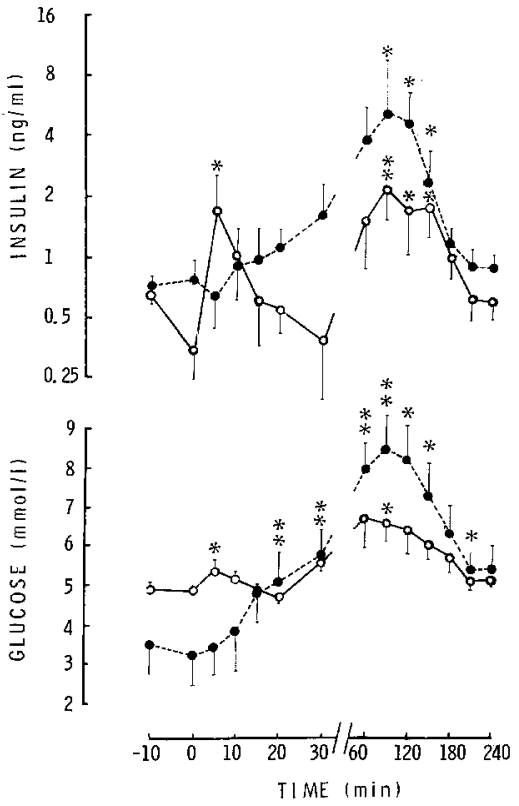

Fig. 1. Mean plasma glucose and insulin concentrations in a group of 4 lambs after ingestion by sucking from a teat of $200 \mathrm{ml}$ milk formula at 1 day of age $(\bullet---\bullet)$ or $250 \mathrm{ml}$ milk at 7 days of age $(\mathrm{O}-\mathrm{O})$. Lambs were fasted overnight before each study. Insulin concentrations are plotted on a log scale. Vertical lines indicate standard errors. The significance of differences from mean prefeeding concentrations by paired t-test are shown *p $<0.05$, $*$ p $<0.01$

suckling before this cannot be excluded. For studies on older infants the doe was allowed free access to her litter until $24 \mathrm{~h}$ before an experiment.

\section{Experimental}

\section{a) Lamb Feeding Experiments}

i) Normal Feeds. To study the effect of milk ingestion, blood samples were obtained from lambs before and after a warm milk feed sucked from a bottle. The amount given was commensurate with age as indicated above, and the feed studied was the first of the day when the lambs had fasted for approximately $10-12 \mathrm{~h}$. The lambs did not have access to solid food during the experiments. Blood samples, two pre-feeding controls and a further 12 samples of $2 \mathrm{ml}$, collected at frequent intervals after suckling, were obtained from an indwelling catheter in the inferior vena cava. The catheter was inserted via a branch of the saphenous vein under local anaesthesia at least one day before the experiment.

Four lambs were studied at 1, 4 and 7 days of age. A further 6 lambs were studied between 10 and 46 days of age.

ii) Sham Feeds. To examine the insulin responses to 'sham feeding' six animals (35-62 days of age) were given a bottle containing only 1-2 $\mathrm{ml}$ milk to suck. This they did with their usual vigour for at least one minute. Blood samples were obtained at the usual intervals. Thirty minutes after the 'sham' feed they were given a normal bottle-feed and blood samples were collected for a further $30 \mathrm{~min}$.

iii) Atropine Feeds. To investigate possible autonomic involvement in the early insulin response to suckling 7 lambs (16-71 days of age) were injected IV with $0,2 \mathrm{mg} / \mathrm{kg}$ atropine sulphate (McCar- thys) $30 \mathrm{sec}$ before feeding began. In other respects the protocol was the same as that for normal feeds. In addition samples were obtained from 3 lambs given atropine, but not fed.

\section{b) Rabbit Feeding Experiments}

To examine the effects of natural suckling on plasma insulin concentrations in the neonates a number of litters of various ages were studied ( 1 day, $\mathrm{n}=7 ; 5$ days $\mathrm{n}=5 ; 10$ days $\mathbf{n}=10 ; 15$ days, $n=6$ ). Subsequently a further 8 litters were studied at 1 day of age. After $24 \mathrm{~h}$ of separation, but before the doe had had access once more to the litter two infants were removed to provide control pre-feeding samples. The partition was then opened and the doe allowed to suckle her litter. After suckling had been completed (usually between 2-3 min) the doe was again separated from the litter by closing off the partition. Further infant rabbits were removed as samples where possible (depending on the size of the litter) at 5, 10, 20, 30, 60 and 120 minutes after the doe had first had access. The infant rabbits were killed by cervical dislocation immediately they were removed from the cage. Blood samples were obtained rapidly by an incision which severed the brachial artery in the axilial region and permitted collection into heparinized syringes using a method similar to that of Girard et al. [9]. Blood samples were kept on ice and centrifuged at $4^{\circ}$ to separate plasma.

\section{Analytical}

Plasma concentrations of glucose and insulin were determined as described previously [10]. The radioimmunoassay for insulin utilized a disequilibrium system with talc as adsorbent to separate free from bound insulin. Monocomponent sheep insulin (Eli Lilly Lot 615 1112B-108-J) and Rabbit Insulin (Eli Lilly Lot 615 D63$15 \mathrm{C})$ were used as standards for the assay of lamb and rabbit plasma samples respectively. Since plasma insulin concentrations do not form a normal distribution whereas their logarithms do, concentrations of insulin were converted to their logarithms before calculation of means and standard errors. Statistical significance was established using Student's t-test. In the lamb experiments a paired t-test was used.

\section{Results}

\section{Plasma Glucose and Insulin Responses to Suckling in Lambs}

When lambs at 1 day of age ingested $200 \mathrm{ml}$ milk by sucking from a bottle their plasma glucose and insulin concentrations increased steadily to maximum values 1-2 $\mathbf{h}$ after the feed (Fig. 1). However, when the same lambs were subsequently studied at 7 days of age (Fig. 1) ingestion of milk was followed by a clearly biphasic pattern of insulin release with a significant early peak 5 minutes after the start of sucking and a significantly smaller maximum increment $(1.83 \mathrm{v} 6.24 \mathrm{~m} \mathrm{~mol} / \mathrm{l}, \mathrm{p}<0.02)$ in plasma glucose than at 1 day of age. Studies at 4 days of age yielded patterns of response intermediate between those seen at 1 and 7 days of age. The insulin response was biphasic with an early peak present in 3 of the lambs, the mean concentration in the group doubling in the 

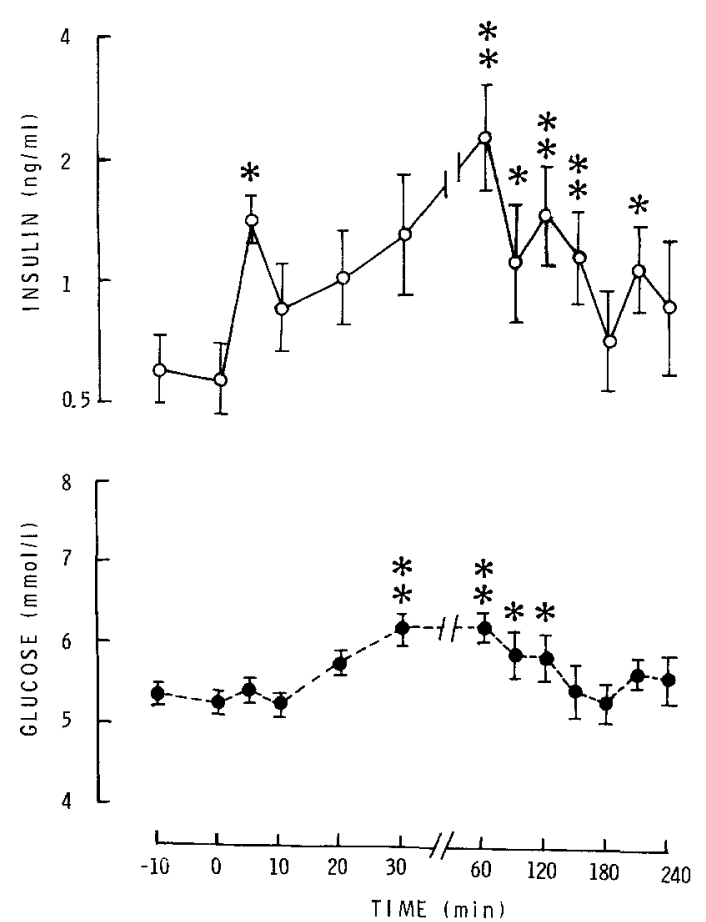

Fig. 2. Mean plasma glucose and insulin concentrations following ingestion of $450 \mathrm{ml}$ milk formula sucked from a teat by 6 lambs, $13-46$ days of age, fasted overnight. Significance of differences from prefeeding values by paired t-test as in Figure 1

first 5 minutes to $1.3 \mathrm{ng} / \mathrm{ml}$ before rising again to a maximum of $2.5 \mathrm{ng} / \mathrm{ml} 60 \mathrm{~min}$ after sucking began. The maximum increase in plasma glucose $(2.68 \mathrm{~m}$ $\mathrm{mol} / \mathrm{l})$ was also less $(\mathrm{p}<0.05)$ than that seen at 1 day of age.

In 6 older lambs (13-46 days of age) the ingestion of $450 \mathrm{ml}$ milk by vigorous sucking from a teat resulted in changes in glucose and insulin concentration (Fig. 2) similar to those seen at 7 days of age. There was a significant increase in plasma insulin 5 minutes after the start of feeding, preceeding the rise in glucose and insulin concentrations between 20 and 60 minutes. The increment in glucose $1.23 \pm 0.13 \mathrm{~m}$ mol/l was again smaller than that at 1 day of age $(\mathrm{p}<0.001)$.

The Effect of 'Sham Feeding' on the Insulin Response to Suckling in Lambs

Allowing 6 lambs (35-45 days of age) to suck from a virtually empty milk bottle resulted in changes in plasma insulin concentration in 3 lambs similar to those seen in the first 30 minutes after a normal feed (Fig. 3). In 3 other lambs sham-fed in this way there was no comparable pattern of changes in plasma insulin. All of the lambs had sucked vigorously on the

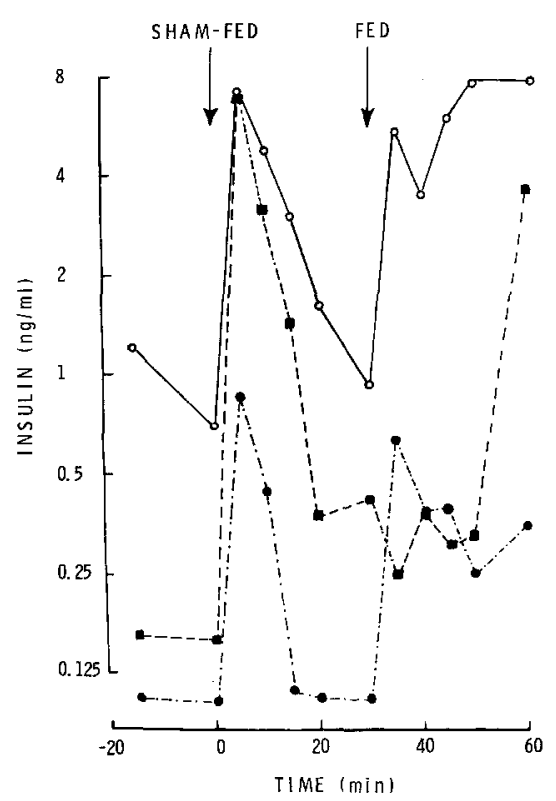

Fig. 3. Plasma insulin concentrations in 3 lambs (fasted overnight) 36-39 days of age after sucking on an empty bottle for $1 \mathrm{~min}$ and then fed $450 \mathrm{ml}$ milk 30 min later
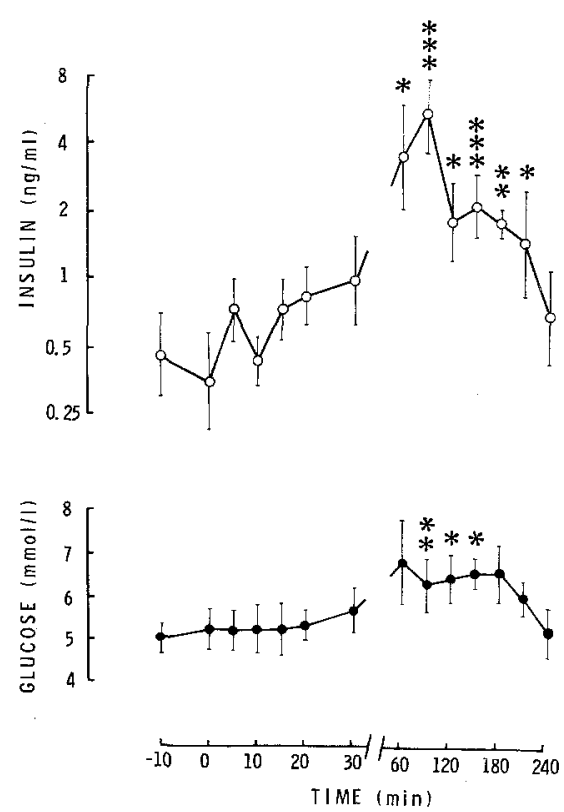

Fig. 4. Mean plasma glucose and insulin concentrations in 7 lambs (16-71 days old, fasted overnight) after ingestion of a milk feed immediately following rapid IV injection of atropine sulphate $(0.2 \mathrm{mg} / \mathrm{kg}) .{ }^{*} \mathrm{p}<0.05,{ }^{* *} \mathrm{p}<0.01,{ }^{* * *} \mathrm{p}<0.001$ 

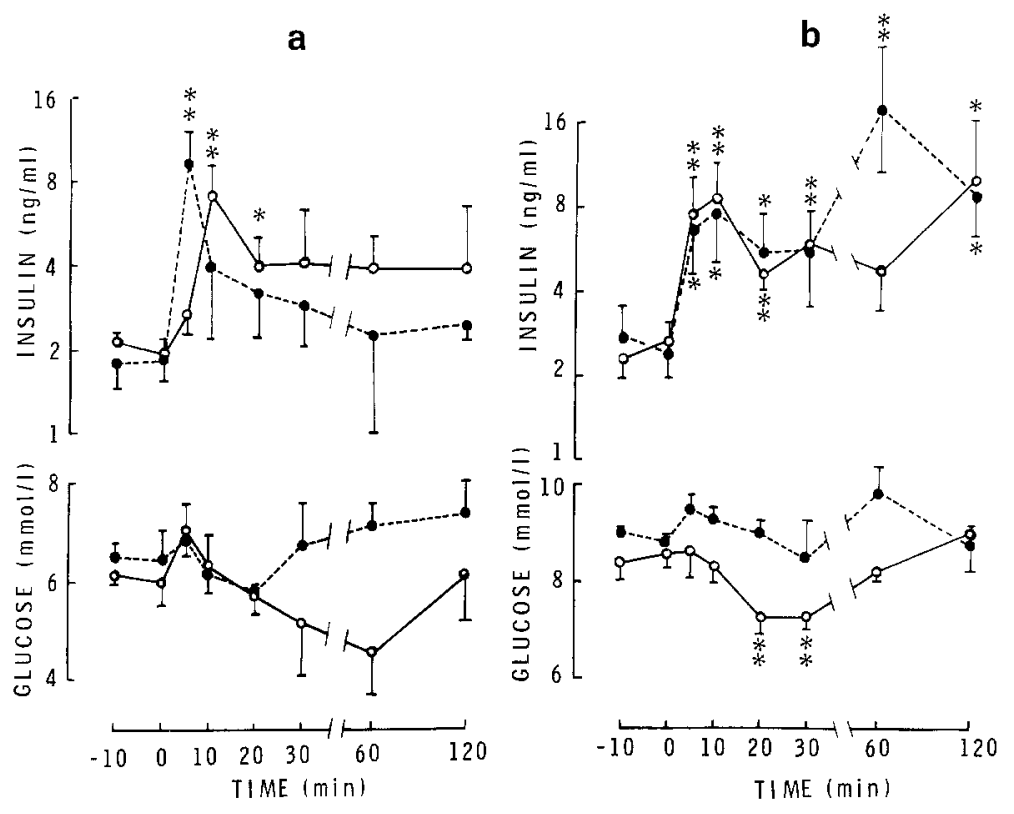

Fig. 5. Mean plasma glucose and insulin concentrations in infant rabbits after natural suckling at a) 1 day old $\left(\mathrm{O} \_\mathrm{O}\right)$ and 5 days old $(\bullet-. \cdot)$ or b) 10 days old $\left(O \_-\circ\right)$ and 15 days old $(\bullet---\bullet)$. Does were separated from their infants for $24 \mathrm{~h}$ before each study. Significance of difference from mean control values $* p<0.05, * * p<0.01$

Table 1. Plasma glucose and insulin concentrations in infant rabbits 1 day of age before and after suckling

\begin{tabular}{lllllll}
\hline Time after suckling commenced $(\mathrm{min})$ & & & & & \\
& -10 & 5 & 10 & 20 & 30 & 60 \\
\hline Glucose $(\mathrm{mmol} / \mathrm{l})$ & $6.01 \pm 0.25$ & $6.82 \pm 0.54$ & $6.11 \pm 0.39$ & $6.55 \pm 0.36$ & $5.70 \pm 0.74$ & $5.95 \pm 0.29$ \\
Insulin $(\mathrm{ng} / \mathrm{ml})$ & & & & & & \\
antilog & 0.57 & $1.41^{\mathrm{a}}$ & $2.15^{\mathrm{b}}$ & $1.79^{\mathrm{b}}$ & $1.83^{\mathrm{b}}$ & $1.07^{\mathrm{a}}$ \\
$\log 10$ mean & $0.753 \pm 0.080$ & $1.147 \pm 0.136$ & $1.332 \pm 0.082$ & $1.253 \pm 0.122$ & $1.262 \pm 0.072$ & $1.029 \pm 0.096$ \\
Number of rabbits & 10 & 9 & 9 & 8 & 4 & 6
\end{tabular}

Results are presented as means \pm SEM

Significance of difference from control value: ${ }^{a} p<0.05, \quad{ }^{b} p<0.01$

teat for at least 1 minute. When 30 minutes later, the lambs were fed normally an early insulin response was again seen in only some of the lambs. There were no significant alterations in plasma glucose in any of the lambs during the 30 minutes following sham feeding.

\section{The Effect of Atropine on the Response to Feeding in Lambs}

The pattern of response to a normal milk feed after prior atropinisation $(0.2 \mathrm{mg} / \mathrm{kg}$ atropine sulphate $)$ in 7 lambs ranging in age from 16 to 71 days is shown in Fig. 4. Atropinisation abolished the early insulin response. Atropine alone had no significant effect on insulin or glucose concentrations in unfed lambs.

\section{Plasma Glucose and Insulin Responses to Natural Suckling in Infant Rabbits}

Following natural suckling, milk in the stomach of infant rabbits comprised $15-30 \%$ of their bodyweight even at 1 day of age. This substantial intake of milk was associated with a clearly biphasic pattern of insulin release over the first two hours after the feed (Fig. 5). There was a pronounced early peak in plasma insulin 5 to 10 minutes after the start of suckling. There were no significant changes in plasma glucose during the first 10 minutes but 20 to 30 minutes after the feed glucose concentration in the 15 day infant rabbits was significantly reduced.

In 1 day old rabbits it appeared that the increase in insulin occurred more slowly than in the older infants. Observations on a further 8 litters at 1 day of age (Table 1) confirmed this. Although insulin concentrations were lower than in the first series and were significantly increased 5 minutes after the start of suckling concentrations were considerably further increased at 10 minutes. There were no associated changes in glucose concentrations.

\section{Discussion}

In previous studies on adult sheep and lambs, 28 days of age or older, [6] it was shown that ingestion of 
food, either of dry food by normal eating or of milk by sucking, was associated with apparently reflex release of insulin prior to any change in plasma metabolite concentrations resulting from absorption of digested nutrients. The results presented here confirm this finding and indicate that the early insulin response to milk ingestion is present within a few days of birth, suggesting that it may be an important component of the anticipatory mechanisms regulating utilization of absorbed nutrients in the neonate. The absence of the response in the one-day old lambs suggests, however, that its development may be postnatal and related to experience of oral food ingestion. On the other hand fetal lambs in utero are known to swallow large quantities of amniotic fluid for many weeks before term [11] and will readily suck on a teat or finger if delivered prematurely. The absence of an early insulin response to feeding at 1 day of age may therefore be related to the stress of adapting to bottle feeding on a milk substitute, although this was not evident, rather than to a developmental change.

The studies show that the early insulin release also occurs in infant rabbits when they suckle naturally, removing any doubt about the physiological relevance of this observation. Whether the slight delay in the early insulin rise in the one-day old rabbits indicates that the mechanisms are not fully mature at birth in this species, include greater involvement of inhibitory factors (such as sympathetic stimulation), or simply reflect less vigorous suckling, cannot be decided satisfactorily from the present experiments. Nevertheless it is evident that in both lambs and infant rabbits a reflex insulin secretory response to sucking is quickly established after birth if not already present at this time.

An early rise in insulin release similar to that seen in the present studies on lambs and infant rabbits has now been observed to occur during eating in a wide variety of species and a number of experiments indicates the reflex nature of its stimulation. It does not seem to depend on the quantity of food consumed since it can be stimulated during sham feeding by a variety of methods $[5,6,7,12]$ including sucking on an empty bottle as shown here and even by the mere anticipation of a meal $[13,14]$, whereas it is generally absent when food is infused into the stomach. Total vagotomy abolishes the response in the rat [8] and the effects of atropinisation in the present study are consistent with a role for the vagus.

The present studies give no indication about the mechanisms by which this reflex release of insulin is brought about. Direct stimulation of the pancreatic islets through their vagal innervation seems most likely as both $\beta$-adrenergic and cholinergic stimulation of pancreatic islets enhances insulin release [15-18]. However involvement of a humoral loop through stimulation of gastro-intestinal hormone release cannot be entirely dismissed.

Recent observations by de Jong et al. [19] indicate that the ventromedial and lateral hypothalamic areas may be involved in the response in rats. The failure in their studies of atropine to block the responses to hypothalamic stimulation is taken to indicate that cholinergic mechanisms are not involved but the efferent pathways have not been defined.

Our results in lambs suggest that the early rise in insulin post-prandially may have homeostatic significance. With the advent of this anticipatory response, the rises in glucose levels concequent upon the meal are reduced. Steffens [20] also found that the early release of insulin was of importance in reducing the magnitude of the excursion in blood glucose concentration following its oral ingestion in rats. It is clear therefore that this early insulin release in an important component of the anticipatory reflex cardiovascular and endocrine changes which occur on ingestion of a meal and evidently comes into play shortly after birth when intermittent oral ingestion of nutrients first becomes of significance. Indeed it is possible that this anticipatory reflex release of insulin may be of greater significance for glucose homeostatic regulation in the newborn than the increased responsiveness of the $\beta$-cell to glucose demonstrated in newborns of several species after initiation of feeding [10, 21-23]. Clearly the oral stimulus should be preserved wherever possible in feeding regimes for sick newborn infants.

Acknowledgements. R. J. P. was supported by a Medical Research Council Scholarship. Sheep and Rabbit Insulin Standards were generously provided by Dr. Mary Root of Eli Lilly \& Co. Indianapolis, Indiana, USA

\section{References}

1. McIntyre, N., Holdsworth, C. D., Turner, D. S.: Intestinal factors in the control of insulin secretion. J. Clin. Endocrinol. Metab. 25, 1317-1324 (1965)

2. Perley, M. J., Kipnis, D. M.: Plasma insulin responses to oral and intravenous glucose: studies in normal and diabetic subjects. J. Clin. Invest. 46, 1954-1962 (1967)

3. Dupré, J., Curtis, J. D., Unger, R. H., Waddell, R. W., Beck, J. C.: Effects of secretin, pancreozymin or gastrin on the response of the endocrine pancreas to glucose or arginine in man. J. Clin. Invest. 48, 745-757 (1969)

4. Karamanos, B., Butterfield, W.J.H., Asmal, A.C. \& Whichelow, M. J.: The pattern of early insulin response to oral glucose. Postgrad. Med. J. 47, 440-443 (1971)

5. Fischer, U., Hommel, H., Ziegler, M., Michael, R.: The mechanism of insulin secretion after oral glucose administration 1, Multiphasic course of insulin mobilization after oral administration of glucose in conscious dogs. Differences to the behaviour after intravenous administration. Diabetologia 8, 104-110 (1972) 
6. Bassett, J. M.: Early changes in plasma insulin and growth hormone levels after feeding in lambs and adult sheep. Aust. J. Biol. Sci. 27, 157-166 (1974)

7. Strubbe, J.H., Steffens, A. B.: Rapid insulin release after ingestion of a meal in the unanaesthetized rat. Am. J. Physiol. 229, 1019-1022 (1975)

8. Louis-Sylvestre, J.: Preabsorptive insulin release and hypoglycemia in rats. Am. J. Physiol. 230, 56-60 (1976)

9. Girard, J. R., Kervran, A., Soufflet, E., Assan, R.: Factors affecting the secretion of insulin and glucagon by the rat fetus. Diabetes 23, 310-317 (1974)

10. Bassett, J. M., Thorburn, G. D.: The regulation of insulin secretion by the ovine fetus in utero. J. Endocrinol. Metab. 50, 59-74 (1971)

11. Bradley, R. M., Mistretta, C. M.: Swallowing in fetal sheep. Science 179, 1016-1017 (1973)

12. Hommel, H., Fischer, U., Retzlaff, K. \& Knöfler, H.: The mechanism of insulin secretion after oral glucose administration. II. Reflex insulin secretion in conscious dogs bearing fistulas of the digestive tract by sham feeding of glucose or tap water. Diabetologia 8, 111-116 (1972)

13. Goldfine, I. D., Abraira, C., Gruenwald, D., Goldstein, M. S.: Plasma insulin levels during imaginary food ingestion under hypnosis. Proc. Soc. Exp. Biol. Med. 133, 274-276 (1970)

14. Parra-Covarrubias, A., Rivera-Rodriguez, I., AlmarezUgalde, A.: Cephalic phase of insulin secretion in obese adolescents. Diabetes 20, 800-802 (1975)

15. Daniel, P. M., Henderson, J. R.: Effect of vagal stimulation on plasma insulin and glucose levels in the baboon. J. Physiol. (Lond). 192, 317-327 (1967)

16. Malaisse, W., Malaisse-Lagae, F., Wright, P. H., Ashmore, J.: Effects of adrenergic and cholinergic agents upon insulin secretion in vitro. Endocrinology 80, 975-978 (1967)
17. Porte, D., Girardier, L., Seydouz, J., Kanamura, Y., Posternak, J.: Neural regulation of insulin secretion in the dog. J. Clin. Invest. 82, 210-214 (1973)

18. Bassett, J. M.: Metabolic effects of catecholamines in sheep. Aust. J. Biol. Sci. 23, 903-914 (1970)

19. de Jong, A., Strubbe, J.H., Steffens, A. B.: Hypothalamic influence on insulin and glucagon release in the rat. Am. J. Physiol. 233, E380-E388 (1977)

20. Steffens, A. B.: Influence of the oral cavity on insulin release in the rat. Am. J. Physiol. 230, 1411-1415 (1976)

21. Asplund, K.: Effects of post-natal feeding on the functional maturation of pancreatic islet beta cells of neonatal rats. Diabetologia 8, 753-759 (1972)

22. Gentz, J., Persson, B., Kelhorn, M., Bengtsson, G., Thorell, J.: Effect of feeding on IV glucose tolerance and insulin response in piglets during the first day of life. Life Sci. 10, 137-144 (1971)

23. Milner, R. D. G.: Secretion of insulin from fetal and post-natal rabbit pancreas in vitro in response to various substances. $J$. Endocrinol. Metab. 44, 267-272 (1969)

Received: March 20, 1978

and in revised form: October 11, 1978

Dr. J. M. Bassett

Nuffield Institute for Medical Research

Headley Way

Headington

Oxford OX3 9DS

England

Responsible for the text: Prof. K. G. M. M. Alberti, Department of Clinical Biochemistry, Royal Victoria Infirmary, Newcastle-upon-Tyne NE1 4LP, England Responsible for advertisements: L. Siegel, B. Schultz, Kurfürstendamm 237, D-1000 Berlin 15, Springer-Verlag Berlin-Heidelberg-New York Printed in Germany by aprinta, Wemding 